\title{
XXIV. \\ Einige Bemerkungen über den Nachweis intravitaler Gefässverstopfungen durch die Methode der Selbstfärbung.
}

\author{
Von Oscar Silbermann in Breslau.
}

Im 121. Bande (Heft 3 S. 605) dieses Archivs hat Herr Prof. Filehne die Methode der Selbstinjection für den Nachweis intravitaler Gefässverstopfungen als die seinige reclamirt mit dem Bemerken, er habe dieselbe durch mich nur zuerst "anwenden" lassen. Wie unbegründet diese Reclamation ist, geht wohl zunächst aus dem Umstande hervor, dass Herr Prof. Filehne, obgleich meine (im 117. Bande dieses Archivs publicirte) Arbeit seiner genauen Durchsicht vor ihrem Erscheinen unterlag, in derselben einen derartigen Anspruch mit keinem Worte erwähnen lässt. - Ebensowenig gesehieht dies in einigen anderen Arbeiten des Breslauer pharmakologischen Instituts, welche später, als die meinige, ersebienen sind und sich behufs Feststellung der gerinnungserregenden Eigenschaften gewisser Blutkörperchengifte dieser Methode bedienen. - Ferner erlaube ich mir darauf binzuweisen, dass diese Selostfärbung der Versuchsthiere zur Ermittelung intravitaler Gefässverscbliessungen schon vor Jabren van anderen Forschern, wie Naunyn, Gohnheim und Litten, angewandt worden ist und dass demnach im vorliegenden Falle von einer neuen, einen Prioritätsanspruch erheischenden Methode doch kaum die Rede sein kann. - Was nun die Anwendung der Selbstinjection bei unseren Experimenten betrifft, so veranlasste ich dieselbe auf Grund gewisser anatomischer Befunde, welche mit den von Arm. Köhler bescbriebenen grosse Aehnlichkeiten aufwiesen und desbalb mir die Vermutbung nahe legten, dass es sich auch bei unseren Vergiftungen um das Vorhandensein von Capillarthrombosen handeln dürfte. In gemeinsamer Besprechung entscbieden wir uns nun, nachdem meinerseits der Experimente der obengenannten Forscher Erwähnung gethan war, für die Metbode der Selbstfärbung und benutzten zunächst hierbei das Indigearmin, später das Phloxin und Eosin. Angesichts dieser Sachlage bin ich wobl an den durch die Methode der Selbstinjection bei unseren Versuchstbieren erhobenen Befunden zablreicher Capillarverstopfungen zum mindesten so sebr betheiligt, als Herr Prof. Filehne, dessen Erklärung, er bätte die Selbstfärbung durch mich nur zuẹst „anwenden" lassen, nach dew oben Mitgetheilten als durchaus ungerechtfertigt erscheinen muss ${ }^{1}$ ).

I) Obige Bemerkungen betreffende briefliche Mittheilung an den Herausgeber. - - - Für die freundliche Uebersendung jener "Bemerkungen" sage ich Ihnen meinen verbindlichsten Dank! Ich habe von ibnen Kenntniss genommen. Auf eine Erwiderung verzichte ich. Wilh. Filehne. 